\title{
Mean temperature of the catch (MTC) in the Greek Seas based on landings and survey data
}

\author{
Athanassios C. Tsikliras ${ }^{1 *}$, Panagiota Peristeraki ${ }^{2}$, George Tserpes $^{2}$ and \\ Konstantinos I. Stergiou ${ }^{1,3}$ \\ 'Laboratory of Ichthyology, Department of Zoology, School of Biology, Aristotle University of Thessaloniki, Thessaloniki, \\ Greece, ${ }^{2}$ Institute of Marine Biological Resources and Inland Waters, Hellenic Centre for Marine Research, Heraklion, \\ Greece, ${ }^{3}$ Institute of Marine Biological Resources and Inland Waters, Hellenic Centre for Marine Research, Athens, Greece
}

\section{OPEN ACCESS}

Edited by:

Manuel J. Zetina-Rejón Instituto Politecnico Nacional-Centro Interdisciplinario de Ciencias Marinas,

Mexico

Reviewed by:

Fabio Pranovi,

University of Venice, Italy

Sanja Matic-Skoko,

Institute of Oceanography and

Fisheries, Croatia

Pablo Del Monte,

Centro Interdisciplinario de Ciencias

Marinas, Mexico

*Correspondence:

Athanassios C. Tsikliras,

Laboratory of Ichthyology, Department of Zoology, School of Biology, Aristotle University of Thessaloniki, University

Campus, UP Box 134, Thessaloniki, 54124, Greece atsik@bio.auth.gr

Specialty section:

This article was submitted to Marine Fisheries, Aquaculture and Living Resources, a section of the journal Frontiers in Marine Science

Received: 12 February 2015 Accepted: 13 April 2015 Published: 28 April 2015

Citation:

Tsikliras AC, Peristeraki P, Tserpes G and Stergiou KI (2015) Mean temperature of the catch (MTC) in the Greek Seas based on landings and survey data. Front. Mar. Sci. 2:23. doi: 10.3389/fmars.2015.00023
The mean temperature of the catch (MTC), which is the average inferred temperature preference of the exploited species weighted by their annual catch, is an index that has been used for evaluating the effect of sea warming on marine ecosystems. In the present work, we examined the effect of sea surface temperature (SST) on the catch composition of the Greek Seas using the MTC applied on the official catch statistics (landings) for the period 1970-2010 (Aegean and Ionian Seas) and on experimental bottom trawl survey data for 1997-2014 (southern Aegean Sea). The MTC of the landings for the study period increased from 11.8 to $16.2^{\circ} \mathrm{C}$ in the Aegean Sea and from 10.0 to $14.7^{\circ} \mathrm{C}$ in the Ionian Sea. Overall, the rate of MTC increase was $1.01^{\circ} \mathrm{C}$ per decade for the Aegean and $1.17^{\circ} \mathrm{C}$ per decade for the lonian Sea and was positively related to SST anomalies in both areas. For the survey data, the increase of the MTC of the bottom trawl catch in the southern Aegean Sea was lower $\left(0.51^{\circ} \mathrm{C}\right.$ per decade) but referred to a shorter time frame and included only demersal species. The change in MTC of official and survey catches indicates that the relative catch proportions of species preferring warmer waters and those preferring colder waters have changed in favor of the former and that this change is linked to SST increase, both internally [through the Atlantic Multidecadal Oscillation(AMO)] or externally (warming trend) driven.

Keywords: marine fishes, SST, AMO, Aegean sea, Ionian sea

\section{Introduction}

The effect of sea temperature increase (Levitus et al., 2000; for the Mediterranean Sea see Bethoux and Gentili, 1999) on the distribution and abundance of marine fish populations is well established for the Mediterranean Sea (e.g., Sabates et al., 2006; Tsikliras, 2008; Tzanatos et al., 2014). Besides the distribution and biomass of marine populations (Cheung et al., 2010) and their community structure (Stenseth et al., 2002), sea warming may affect the biological characteristics of a population including somatic growth (Brander, 1995), onset and duration of spawning (Tsikliras et al., 2010), and length/age at maturity (Tsikliras and Stergiou, 2014a, 2015). The effect of sea warming on marine populations may be direct, through individual physiological adaptations, and indirect, through alterations in the abiotic environment and prey availability (Tzanatos et al., 2014).

The effect of sea warming on the marine faunal composition is particularly evident in the eastern Mediterranean Sea because of the invasion of alien species of indo-pacific origin through 
the Suez Canal (Lessepsian immigrants), which is facilitated by temperature increase (Golani et al., 2002). Over 435 species have invaded the Mediterranean Sea through the Suez Canal, about $50 \%$ of which are molluscs and arthropods and $20 \%$ are fishes (Nunes et al., 2014). These invaders, some of which have established viable populations, certainly change the faunal composition but may also cause severe alterations to ecosystem structure and function (Sala et al., 2011; Bianchi et al., 2014). In certain areas of the eastern Mediterranean some alien fishes are commercially exploited (Kallianiotis and Lekkas, 2005; Giakoumi, 2014) but their catches are not yet officially recorded (Tsikliras and Stergiou, 2014b), at least not as separate records.

The mean temperature of the catch (MTC), which is the average inferred temperature preference of the exploited species weighted by their annual catch, is an index that has been used for evaluating the effect of sea warming on fisheries catches and marine ecosystems (Cheung et al., 2013). According to Cheung et al. (2013), the global MTC increased at a rate of $0.19^{\circ} \mathrm{C}$ per decade and is positively related to the change in sea surface temperature (SST) in most large marine ecosystems of the world (Cheung et al., 2013). The MTC has been recently tested for the western, central and eastern subareas of the Mediterranean Sea (Tsikliras and Stergiou, 2014b). The rate of MTC increase in the eastern Mediterranean, which includes the subdivisions of Aegean Sea (NE) and Levantine Sea (SE), was considerably lower compared to the other Mediterranean subareas (Tsikliras and Stergiou, 2014b), but higher compared to the global average (Cheung et al., 2013). The Ionian Sea, part of which is exploited by the Greek fleet, is included in the central Mediterranean subarea, the one with the highest rate of MTC increase since 1970 (Tsikliras and Stergiou, 2014b).

The objective of the present work was to examine the effect of SST, on the catch composition of the Greek Seas through the MTC approach using data from official catches (landings) and scientific surveys. In the case of MTC, the advantage of using data from surveys is that they may include the catches of Lessepsian migrants that are not yet officially recorded by the local authorities (Tsikliras and Stergiou, 2014b). Therefore, the true contribution of the Lessepsian species to the MTC can be unmasked. In addition, we tested for the effect of large-scale climatic variability on MTC, by examining the effect of North Atlantic Oscillation (NAO) and Atlantic Multidecadal Oscillation (AMO) that have a specific periodicity and have been reported to affect the biomass of some Mediterranean fish stocks (Alheit et al., 2014).

\section{Materials and Methods}

The annual catches ( $t$ ) for the fish, crustacean and cephalopod species of the Greek part of the Aegean and Ionian Seas were extracted from the General Fisheries Commission for the Mediterranean (GFCM) database of the Food and Agricultural Organization (FAO) using the FishSTAT J programme (FAO, 2013). The GFCM data refer to the legal and reported fisheries catches expressed as live weight equivalent of landings and excluding discarded catch, illegal, unreported, recreational, subsistence, and sport fishing. These catches were available for the period 1970-2010 on a species or group of species basis for all Mediterranean subareas/subdivisions and countries. According to the GFCM geographical division of the Mediterranean Sea to subareas, the Ionian Sea is part of the central Mediterranean and the Aegean Sea part of the eastern Mediterranean subarea (Tsikliras et al., 2015).

We also used the catches derived from the bottom trawl experimental surveys performed in the southern Aegean Sea since 1997 within the framework of the MEDITS (International bottom trawl survey in the Mediterranean) survey. The MEDITS surveys have been conducted annually from 1994 to 2006 (with the exception of 2002), and then again in 2008 and 2014. Experimental trawling was conducted according to a standardized protocol (see Bertrand et al., 2002 for details) in predefined stations over the continental shelf and slope (10$800 \mathrm{~m}$ depth). For each year, excluding 1994-1996 due to changes in the sampling scheme that occurred in 1996, the catch (in terms of biomass) by species was recorded and used in the present work. Rare species with very low (less than $1 \mathrm{~kg}$ ) annual catch, were excluded from the analysis.

The preferred temperatures (median, 25th and 75th percentile) were acquired from the supplementary material that is available in Cheung et al. (2013) for all species. Species of the GFCM database that appeared grouped at family or higher taxonomic level and species for which the temperature preferences were not available were excluded from the analysis.

The MTC was calculated for the 61 species (51 fishes, 5 crustaceans, and 5 cephalopods; bivalves and corals were excluded from the analysis) that are being officially recorded in the Ionian and the Aegean Sea and for the 112 species (97 fishesof which 25 elasmobranchs -6 crustaceans, 9 cephalopods; bivalves and corals were excluded from the analysis) caught during the experimental trawl surveys. MTC was calculated annually (1970-2010 for the official catches and 1997-2014 for the survey data) per area based on the median temperature preference of each species that was weighted by its catch, according to the following equation (Cheung et al., 2013):

$$
\operatorname{MTC}_{y r}=\frac{\sum_{i}^{n} T_{i} C_{i, y r}}{\sum_{i}^{n} C_{i, y r}}
$$

where $C_{i, y r}$ are the catches of species $i$ in the Greek Seas for year $y r, T_{i}$ is the median temperature preference of species $i$ and $n$ is the total number of species in the annual catch.

Mean annual SST data for the Aegean Sea (40.37 N, 24.75 E) and for Ionian Sea $(39.01 \mathrm{~N}, 20.10 \mathrm{E})$ were downloaded from the National Oceanic and Atmospheric Administration (NOAA, US Department of Commerce, www.noaa.gov) for the period 1970-2010. MTC needs to be correlated against large-scale climatic variability to exclude their effect on fish catches. For that reason, the annual numerical values of NAO and AMO indices were downloaded from the National Oceanic and Atmospheric Administration (NOAA, US Department of Commerce, www. noaa.gov) for the same period of time.

The relationships of MTC of the official catches with SST, AMO and NAO were explored with cross-correlation. 
Durbin-Watson statistic was used to test for serial correlation between the variables.

\section{Results}

The records for which the inferred temperature preference was available and were used for the calculation of the MTC represented $82 \%$ of Aegean $(57,250 \mathrm{t}$ out of $69,800 \mathrm{t}$ caught in 2010 ) and $78 \%$ of Ionian Sea (6050 t out of $7800 \mathrm{t}$ caught in 2010) catches.

Based on the officially recorded catch statistics, MTC increased from $11.8^{\circ} \mathrm{C}$ in 1970 to $16.2^{\circ} \mathrm{C}$ in 2010 in the Aegean Sea and from $10.0^{\circ} \mathrm{C}$ in 1970 to $14.7^{\circ} \mathrm{C}$ in 2010 in the Ionian Sea (Figure 1). Overall, the rate of MTC increase was $1.01^{\circ} \mathrm{C}$ per decade for the Aegean and $1.17^{\circ} \mathrm{C}$ per decade for the Ionian Sea (Figure 1). The increase of MTC in both Ionian and Aegean Seas was positively related to SST anomalies (Figure 1; columns). At time lag 0, the relationship was stronger for the Aegean Sea (correlation coefficient $=0.56, P=0.0002$ ), compared to the Ionian Sea (correlation coefficient $=0.51$, $P=0.0007)$. According to Durbin-Watson statistic there was an indication for serial correlation in both areas. After accounting for serial correlation, the highest correlation for Aegean Sea was observed at time lag 1 (correlation coefficient $=0.60, P<0.001$ ), whereas for Ionian Sea at time lag 2 (correlation coefficient $=$ $0.66, P<0.001)$. The increase of MTC in both Ionian and
Aegean Seas was also positively related to AMO index (Figure 1; shaded area). The highest correlation was observed at time lag 0 for the Ionian Sea (correlation coefficient $=0.63, P<0.001$ ) and at time lag 1 for the Aegean Sea (correlation coefficient $=0.70$, $P<0.001)$. There was no correlation between MTC and NAO index in any area at all time lags (Aegean Sea: $P>0.30$ in all cases; Ionian Sea: $P>0.05$ in all cases).

The catch of species with inferred temperature preference for waters warmer than $20^{\circ} \mathrm{C}$, plotted as percentage to the total catches, increased compared to those with inferred temperature preference for waters colder than $20^{\circ} \mathrm{C}$, in both areas (Figure 2). The cut-off temperature value was set at $20^{\circ} \mathrm{C}$ because this is the average inferred temperature preference for all species in the dataset. In the Aegean Sea, the catches of species preferring warmer waters quadrupled between 1970 and 2010 (from about $5000 \mathrm{t}$ to about 19,000 t), while those of species preferring colder waters almost doubled (from around 21,000 t to 41,000 t) for the same period (Figure 2). Similarly, in the Ionian Sea, the catches of species preferring warmer waters also quadrupled between 1970 and 2010 (from about $450 \mathrm{t}$ to about $1800 \mathrm{t}$ ), while those of species preferring colder waters also doubled (from around 2000 t to $4200 \mathrm{t}$ ) for the same period (Figure 2).

Based on the survey data, the southern Aegean Sea MTC increased from $18.5^{\circ} \mathrm{C}$ in 1997 to $19.6^{\circ} \mathrm{C}$ in 2008 and then declined to $19.0^{\circ} \mathrm{C}$ in 2014 . The rate of MTC increase was $0.51^{\circ} \mathrm{C}$ per decade, which is similar to the rate of MTC

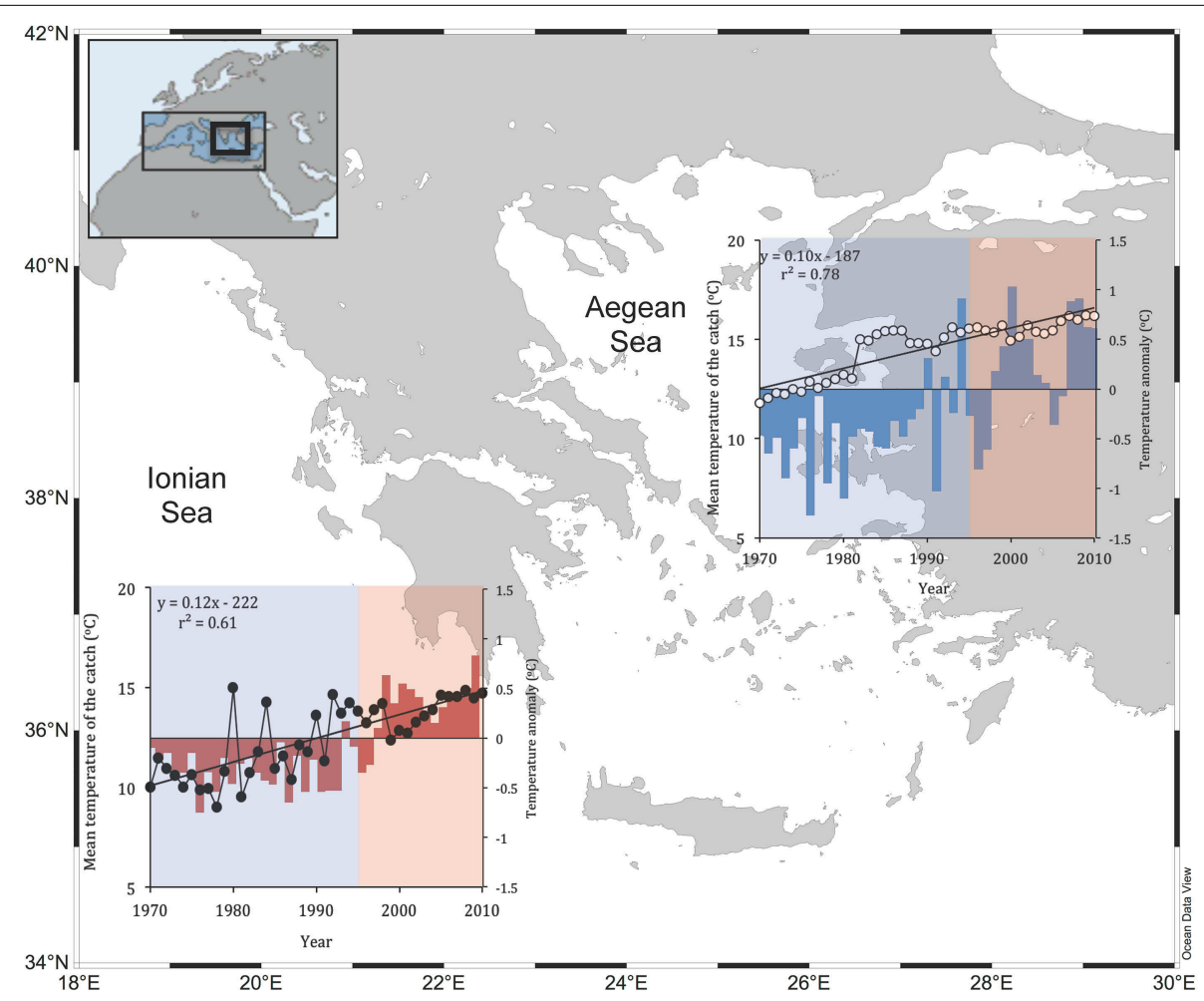

FIGURE 1 | The mean temperature of the catch $\left({ }^{\circ} \mathrm{C}\right.$; Ionian Sea: black dots; Aegean Sea: white dots) based on official landings and sea surface temperature anomaly $\left({ }^{\circ} \mathrm{C}\right.$; Ionian Sea: red bars;
Aegean Sea: blue bars) for the Greek Seas (1970-2010). Shaded areas indicate the positive (red shaded area) and negative (blue shaded area) AMO phases. 


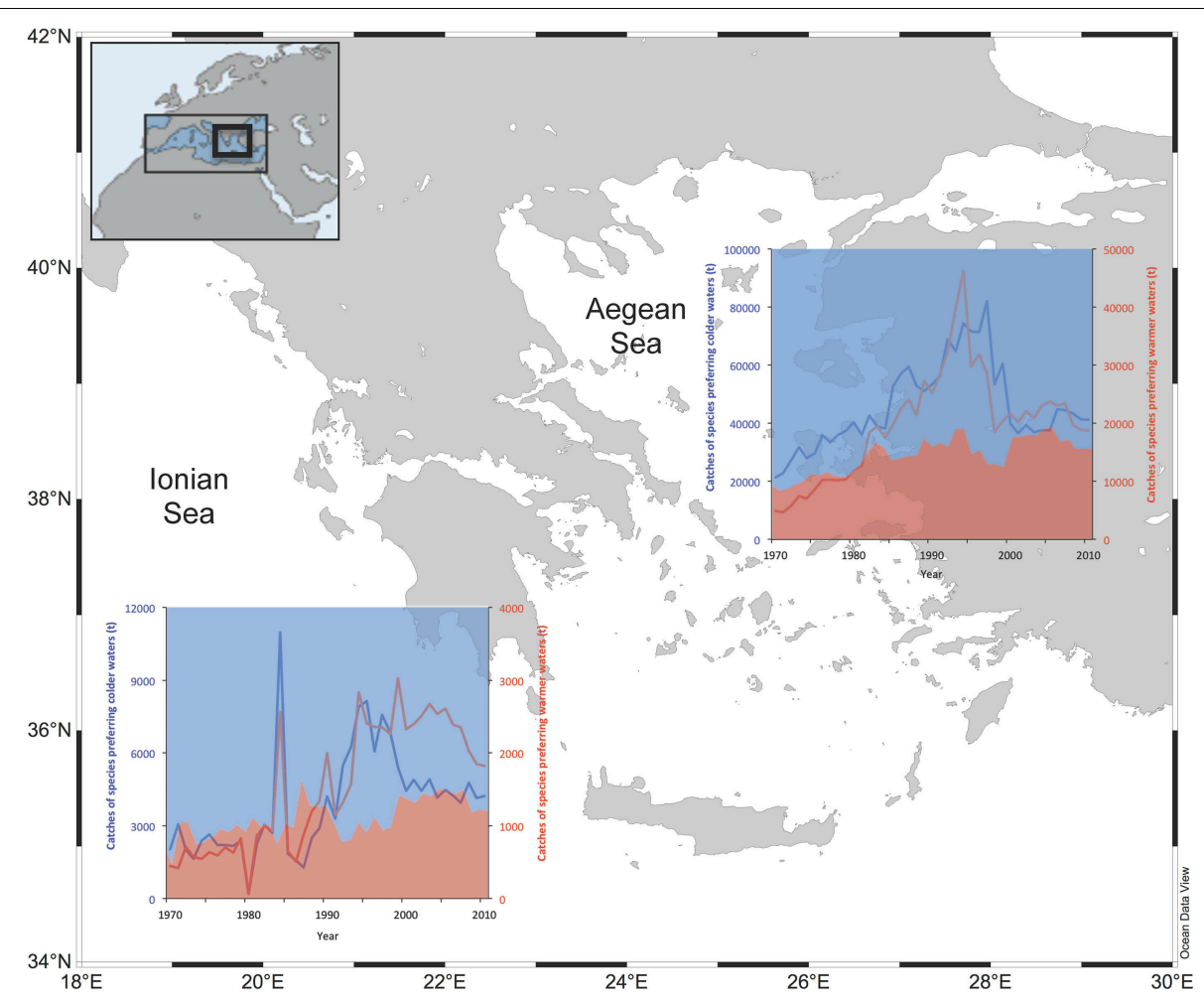

FIGURE 2 | The catches of species with preference for waters warmer than $20^{\circ} \mathrm{C}$ (red line) and those preferring waters colder than $20^{\circ} \mathrm{C}$ (blue lines) based on official landings in Ionian and Aegean Sea (1970-2010). The percentage of these categories to the total catch is shown

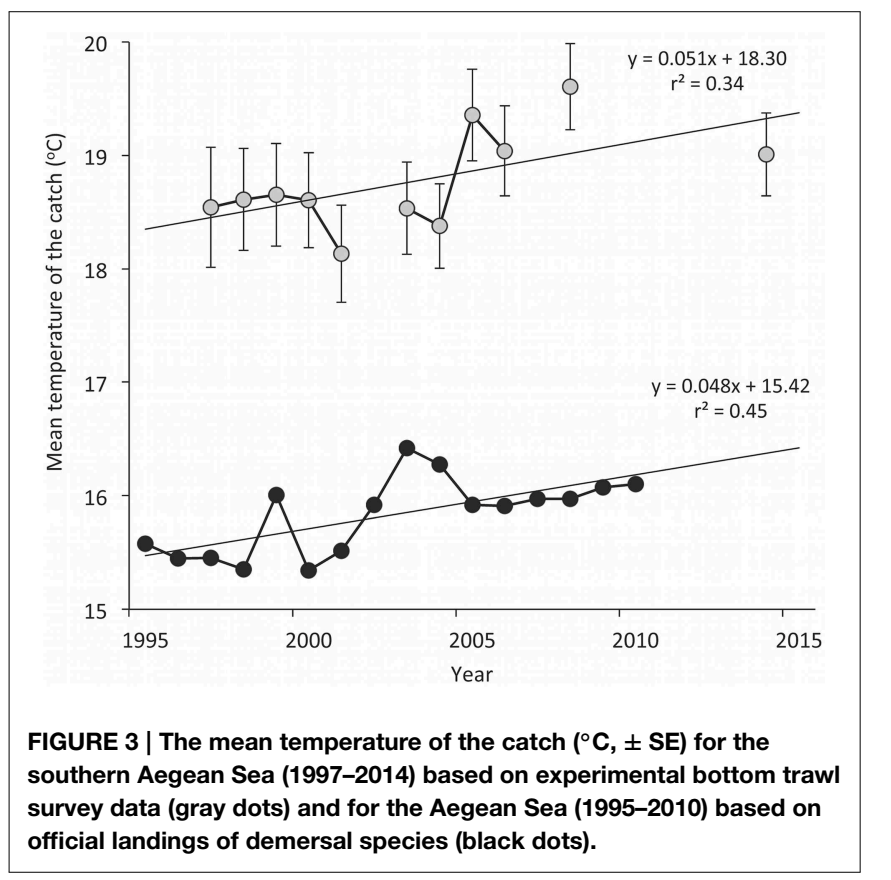

$\left(0.48^{\circ} \mathrm{C}\right.$ per decade) that emerged when only demersal species were included in the official catches dataset (Figure 3). Eight species of Indo-Pacific origin were caught in the experimental in the underlying area plot (blue area: species preferring colder waters; red area: species preferring warmer waters). The cut-off temperature value was set at $20^{\circ} \mathrm{C}$ because this is the average inferred temperature preference for all species in the dataset.

trawl surveys from 2003 to 2014, with an increasing trend in species number with time, which, however, is not significant (Figure 4).

\section{Discussion}

Similarly to what has been recently reported for the Mediterranean subareas (Tsikliras and Stergiou, 2014b), the results of Cheung et al. (2013) that MTC is determined by SST, are also confirmed for the Greek Seas. However, the rate of MTC increase was higher compared to previously reported values for the entire Mediterranean Sea (Cheung et al., 2013), the Mediterranean subareas (Tsikliras and Stergiou, 2014b), and the northeastern Aegean Sea (Keskin and Pauly, 2014). Therefore, the signal of MTC may be stronger when catches are examined at fine scales and at higher taxonomic resolution, as shown for the Greek Seas in the present work.

In principle, MTC increase is an indication of alterations in the relative catch proportions of species showing preference for warmer waters (thermophilous) and those preferring colder waters (psychrophilous), in favor of the former (Cheung et al., 2013). Theoretically, this can be the result of catching higher quantities of thermophilous species or lower quantities of psychrophilous ones, but both conditions may simultaneously hold (Tsikliras and Stergiou, 2014b). In both Ionian and Aegean Seas, the percentage contribution of thermophilous and 


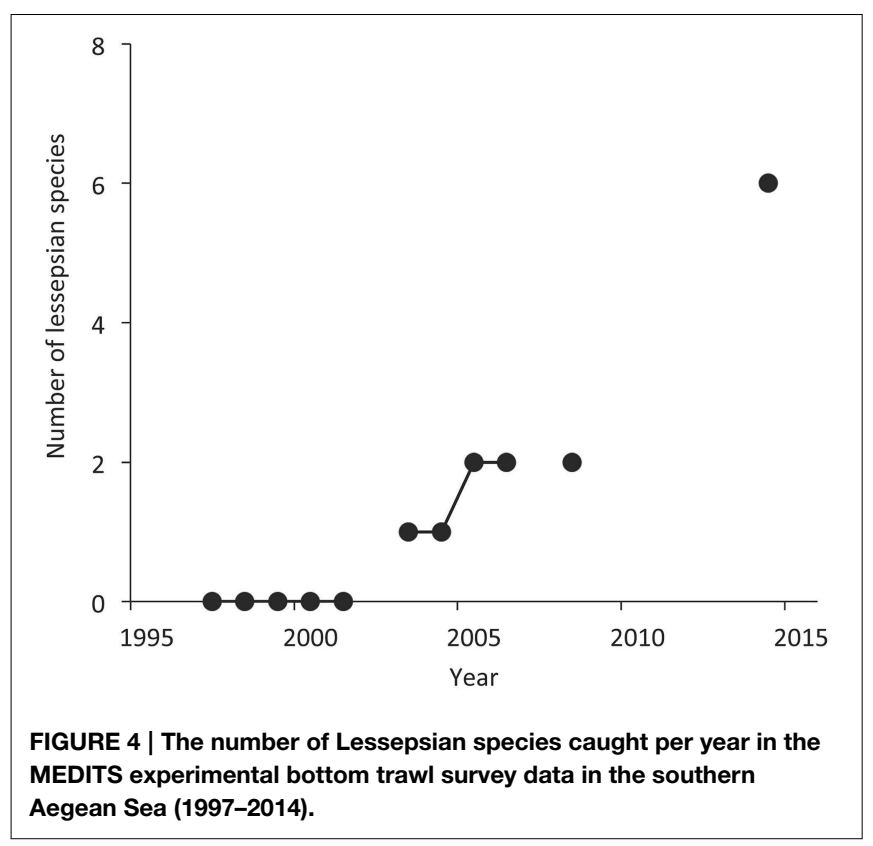

psychrophilous species in the catches changed in favor of the former, and this was because the catches of thermophilous species increased (Figure 2).

Mediterranean SST increase, can be both internally (through the AMO) or externally (warming trend) driven (Matei et al., 2012). The overall SST trend in the Mediterranean over the past 80 years reflects the AMO dynamics, with the warm and cold phases corresponding to those in the North Atlantic and with a period of high SST beginning in the mid 1990s (Marullo et al., 2011; Alheit et al., 2014). Using the magnitude squared coherence, which measures the association and linearity among stationary processes (Wang et al., 2004), it has been shown that all Atlantic time series (NAO, AMO, subpolar gyre, SST, subtropical gyre SST) are significantly coherent with the Mediterranean SST time series (Marullo et al., 2011). Therefore, fish communities in the Mediterranean may also exhibit AMO-related dynamics, as has been recently demonstrated for populations of small pelagic fishes (Alheit et al., 2014).

The effect of NAO on the Mediterranean Sea differs between the eastern and western basins (Marullo et al., 2011; Báez et al., 2013). The correlation of NAO with SST is low for both basins being negative in the eastern basin but only in winter and positive in the western one (Marullo et al., 2011; Skliris et al., 2012). This difference might explain the lack of any correlation between NAO and MTC in the Aegean Sea (eastern Mediterranean) and the weak, but marginally not significant, relationship of NAO and MTC in the Ionian Sea (central Mediterranean).

The effect of new species entering the fisheries can be excluded for the Aegean and Ionian Seas because the list of species that are being routinely recorded by the Greek authorities remains unchanged since 1982. As far as trawl survey data are concerned, two out of the eight lessepsian (i.e., alien species of indo-pacific origin) species that were caught, were included in the analysis, the reticulated leatherjacket Stephanolepis diaspros, and round herring Etrumeus golanii (Peristeraki et al., 2007). In any case, the effect of sea warming on the distribution and biomass of marine populations is evident (Cheung et al., 2013). The change in the MTC is attributed to the sea warming, which facilitated the northward expansion of species with tropical and subtropical distributions (Zenetos et al., 2011). It is certain that the incorporation of the catches of alien species, whose occurrence and biomass are increasing (Peristeraki et al., 2007), will lead to further increase of the MTC because the preferred temperatures of these species are considerably higher compared to species with subtropical and temperate distributions. A potential replacement in the catches of red mullets Mullus spp. with goatfish Upeneus spp. (e.g., Bianchi et al., 2014), of salema Sarpa salpa with spinefoot Siganus spp. (e.g., Giakoumi, 2014), of anchovy Engraulis encrasicolus with round-eye herring E. golanii (e.g., Kallianiotis and Lekkas, 2005) is on the way since there is growing evidence for increasing contribution of alien species of Indo-pacific origin in the Aegean Sea catches (Zenetos et al., 2011). A replacement in the catches of sardine Sardina pilchardus and sprat Sprattus sprattus with round sardinella Sardinella aurita, which is also distributed in the Greek Seas already occurs (Tsikliras, 2008) because of round sardinella's expansion over sardine and/or sprat (Sabates et al., 2006).

Since the catches of alien species of Indo-Pacific origin that have reached the Greek Seas through Suez Canal are not yet being separately recorded, the increase of MTC is attributed to the biomass change of local populations, which are often accompanied by geographic distribution expansions and population outbursts (e.g., round sardinella: Tsikliras, 2008). According to a recent work that examined the relationship of landings with SST on a species basis (Tzanatos et al., 2014), the fisheries landings of around $60 \%$ of the most abundant commercial species were positively (e.g., anchovy) or negatively (e.g., sardine) related to SST. Although the catch/biomass declines are most probably the result of overexploitation, some declines may be related to SST increase, such as the decline of sardine and sprat (Sabates et al., 2006).

The bottom trawl survey catches consist almost exclusively of demersal species, while the official catches also include small, medium and large pelagic species that are more susceptible to temperature fluctuations (Alheit et al., 2014). After accounting for this difference by including only the demersal stocks of the official catches, the rate of MTC increase was very similar between the two datasets (Figure 3). The difference observed in level of MTC between official and survey catches could be attributed to the fact that official catch statistics do not include non-targeted species and those of low or no economic importance that are caught in scientific surveys. The lower rate of MTC increase of the demersal stocks compared to the pelagic ones clearly supports the susceptibility of pelagic species to sea temperature fluctuations (Alheit et al., 2014).

In this work, questions related to the effect of fishing effort were not considered partly because of a lack of significant changes in fishers tactics regarding targeted species and fishing grounds, within the fleet operating in Greek waters (Tzanatos et al., 2014). Nevertheless, the synergistic effects of other processes, including overexploitation, which has been recently documented for the Mediterranean fisheries (Tsikliras et al., 2015), should be carefully examined when referring to species distributions and especially 
to biomass declines. These factors, particularly if fishers remain oriented to targeting indigenous than new species, can disguise the actual relationship between warm water and cold water species and the rate of MTC increase might be underestimated.

\section{References}

Alheit, J., Licandro, P., Coombs, S., Garcia, A., Giraldez, A., Santamaria, M. T. G., et al. (2014). Atlantic Multi-decadal Oscillation (AMO) modulates dynamics of small pelagic fishes and ecosystem regime shifts in the eastern North and Central Atlantic. J. Mar. Syst. 131, 21-35. doi: 10.1016/j.jmarsys.2013. 11.002

Báez, J. C., Gimeno, L., Gómez-Gesteira, M., Ferri-Yáñez, F., and Real, R. (2013). Combined effects of the North Atlantic Oscillation and the Arctic Oscillation on sea surface temperature in the Alborán Sea. PLoS ONE 8:e62201. doi: 10.1371/journal.pone.0062201

Bertrand, J., De Sola, L., Papaconstantinou, C., Relini, G., and Souplet, A. (2002). The general specifications of the MEDITS surveys. Sci. Mar. 66(Supp. 2), 9-17

Bethoux, J. P., and Gentili, B. (1999). Functioning of the Mediterranean Sea: past and present changes related to freshwater input and climate changes. J. Mar. Syst. 20, 33-47. doi: 10.1016/S0924-7963(98)00069-4

Bianchi, C. M., Corsini-Foka, M., Morri, C., and Zenetos, A. (2014). Thirty years after: dramatic change in the coastal marine ecosystemsof Kos Island (Greece), 1981-2013. Medit. Mar. Sci. 15, 482-497. doi: 10.12681/mms.678

Brander, K. M. (1995). The effect of temperature on growth of Atlantic cod (Gadus morhua L.). ICES J. Mar. Sci. 52, 1-10. doi: 10.1016/1054-3139(95)80010-7

Cheung, W. W. L., Lam, V. W. Y., Sarmiento, J. L., Kearney, K., Watson, R., Zeller, D., et al. (2010). Large-scale redistribution of maximum fisheries catch potential in the global ocean under climate change. Glob. Change Biol. 16, 24-35. doi: 10.1111/j.1365-2486.2009.01995.x

Cheung, W. W. L., Watson, R., and Pauly, D. (2013). Signature of ocean warming in global fisheries catch. Nature 497, 365-369. doi: 10.1038/nature12156

FAO. (2013). Fishery Information, Data and Statistics Unit GFCM Capture Production 1970-2010. Rome: FISHSTAT J-Universal software for fishery statistical time series.

Giakoumi, S. (2014). Distribution patterns of the invasive herbivore Siganus luridus (Ruppell, 1829) and its relation to native benthic communities in the central Aegean Sea, Northeastern Mediterranean. Mar. Ecol. 35, 96-105. doi: 10.1111/maec.12059

Golani, D., Orsi-Relini, L., Massuti, E., and Quignard, J. P. (2002). "Fishes," in CIESM Atlas of Exotic Species in the Mediterranean, Vol I, ed F. Briand (Monaco: CIESM Publisher), 1-256.

Kallianiotis, A., and Lekkas, V. (2005). First documented report on the Lessepsian migrant Etrumeus teres De Kay, 1842 (Pisces: Clupeidae) in the Greek Seas. J. Biol. Res. 4, 225-229.

Keskin, C., and Pauly, D. (2014). Changes in the 'Mean Temperature of the Catch': application of a new concept to the North-eastern Aegean Sea. Acta Adriat. 55, 213-218.

Levitus, S., Antonov, J. I., Boyer, T. P., and Stephens, C. (2000). Warming of the world ocean. Science 287, 2225-2229. doi: 10.1126/science.287.5461.2225

Marullo, S., Artale, V., and Santoleri, R. (2011). The SST multidecadal variability in the Atlantic-Mediterranean region and its relation to AMO. J. Clim. 24, 4385-4401. doi: 10.1175/2011JCLI3884.1

Matei, D., Pohlmann, H., Jungclaus, J., Muller, W., Haak, H., and Marotzke, J. (2012). Two tales of initializing decadal climate prediction experiments with the ECHAM5/MPI-OM model. J. Clim. 25, 8502-8523. doi: 10.1175/JCLI-D11-00633.1

Nunes, A. L., Katsanevakis, S., Zenetos, A., and Cardoso, A. C. (2014). Gateways to alien invasions in the European seas. Aquat. Invasions 9, 133-144. doi: 10.3391/ai.2014.9.2.02

\section{Acknowledgments}

The authors would like to thank the three reviewers for their helpful comments.

Peristeraki, P., Lazarakis, G., Skarvelis, K., Georgiadis, M., and Tserpes, G. (2007) Additional records on the occurrence of alien fish species in the eastern Mediterranean Sea. Mediterr. Mar. Sci. 7, 61-67. doi: 10.12681/mms.170

Sabates, A., Martin, P., Lloret, J., and Raya, V. (2006). Sea warming and fish distribution: the case of the small pelagic fish, Sardinella aurita, in the western Mediterranean. Glob. Change Biol. 12, 1-11. doi: 10.1111/j.13652486.2006.01246.x

Sala, E., Kizilkaya, Z., Yildirim, D., and Ballesteros, E. (2011). Alien marine fishes deplete algal biomass in the eastern Mediterranean. PLoS ONE 6:e17356. doi: 10.1371/journal.pone.0017356

Skliris, N., Sofianos, S., Gkanasos, A., Mantziafou, A., Vervatis, V., Axaopoulos, P., et al. (2012). Decadal scale variability of sea surface temperature in the Mediterranean Sea in relation to atmospheric variability. Ocean Dyn. 62, 13-30. doi: 10.1007/s10236-011-0493-5

Stenseth, N. C., Mysterud, A., Ottersen, G., Hurrell, J. W., Chan, K.-S., and Lima, M. (2002). Ecological effects of climate fluctuations. Science 297, 1292-1296. doi: $10.1126 /$ science. 1071281

Tsikliras, A. C. (2008). Climate-related geographic shift and sudden population increase of a small pelagic fish (Sardinella aurita) in the eastern Mediterranean Sea. Mar. Biol. Res. 4, 477-481. doi: 10.1080/17451000802291292

Tsikliras, A. C., Antonopoulou, E., and Stergiou, K. I. (2010). Spawning period of Mediterranean marine fishes. Rev. Fish Biol. Fish. 20, 499-538. doi: 10.1007/s11160-010-9158-6

Tsikliras, A. C., Dinouli, A., Tsiros, V.-Z., and Tsalkou, E. (2015). The Mediterranean and Black Sea fisheries at risk from overexploitation. PLoS ONE 10:e121188. doi: 10.1371/journal.pone.0121188

Tsikliras, A. C., and Stergiou, K. I. (2014a). Size at maturity of Mediterranean marine fishes. Rev. Fish Biol. Fish. 24, 219-268. doi: 10.1007/s11160-013-9330-x

Tsikliras, A. C., and Stergiou, K. I. (2014b). The mean temperature of the catch increases quickly in the Mediterranean Sea. Mar. Ecol. Prog. Ser. 515, 281-284. doi: 10.3354/meps 11005

Tsikliras, A. C., and Stergiou, K. I. (2015). Age at maturity of Mediterranean marine fishes. Mediterr. Mar. Sci. 16, 5-20. doi: 10.12681/mms.659

Tzanatos, E., Raitsos, D. E., Triantafyllou, G., Somarakis, S., and Tsonis, A. A. (2014). Indications of a climate effect on Mediterranean fisheries. Clim. Change 122, 41-54. doi: 10.1007/s10584-013-0972-4

Wang, S. Y., Liu, X., Yianni, J., Miall, R. C., Aziz, T. Z., and Stein, J. F. (2004) Optimizing coherence estimation to assess the functional correlation of tremorrelated activity between the subthalamic nucleus and the forearm muscles. J. Neurosci. Methods 136, 197-205. doi: 10.1016/j.jneumeth.2004.01.008

Zenetos, A., Katsanevakis, S., Poursanidis, D., Crocetta, F., Damalas, D., Apostolopoulos, G., et al. (2011). Marine alien species in Greek Seas: additions and amendments by 2010. Mediterr. Mar. Sci. 12, 95-120. doi: $10.12681 / \mathrm{mms} .55$

Conflict of Interest Statement: The authors declare that the research was conducted in the absence of any commercial or financial relationships that could be construed as a potential conflict of interest.

Copyright (C) 2015 Tsikliras, Peristeraki, Tserpes and Stergiou. This is an open-access article distributed under the terms of the Creative Commons Attribution License (CC $B Y)$. The use, distribution or reproduction in other forums is permitted, provided the original author(s) or licensor are credited and that the original publication in this journal is cited, in accordance with accepted academic practice. No use, distribution or reproduction is permitted which does not comply with these terms. 